\title{
The Stem Heat Balance Method to Measure Transpiration: Evaluation of a New Sensor
}

\author{
Robert J. Lascano ${ }^{*}$, Timothy S. Goebel ${ }^{1}$, Jill Booker ${ }^{1}$, Jeffrey T. Baker ${ }^{2}$, Dennis C. Gitz III ${ }^{1}$ \\ ${ }^{1}$ USDA-ARS, Wind Erosion and Water Conservation Research Unit, Plant Stress and Water Conservation Laboratory, Lubbock, TX, USA \\ ${ }^{2}$ USDA-ARS, Wind Erosion and Water Conservation Research Unit, Plant Stress and Water Conservation Laboratory, Big Spring, TX, \\ USA \\ Email: ${ }^{*}$ Robert.Lascano@ars.usda.gov
}

How to cite this paper: Lascano, R.J., Goebel, T.S., Booker, J., Baker, J.T. and Gitz III, D.C. (2016) The Stem Heat Balance Method to Measure Transpiration: Evaluation of a New Sensor. Agricultural Sciences, 7, 604-620.

http://dx.doi.org/10.4236/as.2016.79057

Received: August 9, 2016

Accepted: September 17, 2016

Published: September 20, 2016

Copyright $\odot 2016$ by authors and Scientific Research Publishing Inc. This work is licensed under the Creative Commons Attribution International License (CC BY 4.0).

http://creativecommons.org/licenses/by/4.0/ (c) (i) Open Access

\begin{abstract}
The measurement of crop transpiration $\left(\mathrm{T}_{\text {crop }}\right)$ under field conditions and throughout the growing season is difficult to obtain. An available method uses stem flow gauge sensors, based on the conservation of energy and mass, where the calculated sap flow $(F)$ is a direct measure of $\mathrm{T}_{\text {crop }}$. This method has been extensively tested on agronomic, horticultural, ornamental aspects and tree crops and the general consensus is that $F$ is a measure of $\mathrm{T}_{\text {crop }}$. A new sap flow gauge (EXO-Skin ${ }^{T M}$ Sap Flow) sensor, with different placement and number of thermocouples, compared to the original sensor, was introduced, resulting in a different energy balance equation to calculate $F$. Our objective was to compare values of $\mathrm{T}_{\text {crop }}$ obtained with the new sensor on cotton (Gossypium hirsutum, L) plants to values measured with lysimeters. For this purpose, cotton plants were grown in 11-liter pots in a greenhouse experiment and hourly and daily values of $\mathrm{T}_{\text {crop }}$ were compared for eight days. We used linear regression analysis to compare the hourly and daily values of $\mathrm{T}_{\text {crop }}$ measured with the sensor to corresponding values measured with lysimeters on the same plant. Using a t-test $(p>0.05)$ we tested if the slope of the line was significantly different than 1 and if the intercept was significantly different than 0 . This test indicated that there were no statistical differences between hourly and daily values of $\mathrm{T}_{\text {crop }}$ measured with the new sensor and with the lysimeters. The main advantage of the new sensor is the flexibility of the new heater, allowing for better thermal contact between the plant stem and the temperature sensors. Further, the new sensor requires less wiring and copper connectors, and the number of channels used in a datalogger to record the output from the sensor is reduced by $25 \%$. We conclude that the new sensor correctly measures $\mathrm{T}_{\text {crop }}$ and that additional experiments with field grown plants are required to test the sensor at higher values of $\mathrm{T}_{\text {crop. }}$.
\end{abstract}




\section{Keywords}

Cotton, Greenhouse, Irrigation, Evaporation, Water Use, Water Management

\section{Introduction}

The process whereby water is transported from the soil to the plant, via the roots, and to the atmosphere, via the stomata in leaves, is called transpiration $\left(\mathrm{T}_{\text {crop }}\right)$, an important component of the water cycle. In agriculture and hydrology, knowledge of $\mathrm{T}_{\text {crop }}$ is important; however, its measurement is difficult, particularly under field conditions and throughout the growing season. In general, the most accurate measurement of $\mathrm{T}_{\text {crop }}$ is gravimetric and under field conditions this is done by using weighing lysimeters [1]-[5], an isolated soil tank mounted on a load cell that directly measures the evaporation of water from the soil $\left(\mathrm{E}_{\text {soil }}\right)$ and plant $\left(\mathrm{T}_{\text {crop }}\right)$, which collectively is referred to as evapotranspiration (ET), i.e., $\mathrm{ET}=\mathrm{E}_{\text {soil }}+\mathrm{T}_{\text {crop }}$. Of importance is the ability to have independent measurements of at least two of the three terms and thus the remaining value may be determined by difference.

The direct measurement of $\mathrm{T}_{\text {crop }}$ under field conditions can be done using several methods that include: a) stem flow gauges [6]-[8]; b) weighing lysimeters [1]-[5]; c) environmental chambers that cover a volume $\left(>1 \mathrm{~m}^{3}\right)$ of plants [9]-[11] and; $\left.\mathrm{d}\right)$ micrometeorological methods, such as the Bowen ratio [12] [13] and Eddy covariance [14] [15]. In general, methods b)-d) are expensive and laborious and thus mainly used for research purposes. Of these methods, method a), i.e., stem flow gauges, is the only direct measure of $\mathrm{T}_{\text {crop }}$ currently available that could be used for routine measurement of crop water use and could be integrated into a water management scheme as a tool for irrigation [16].

The theory of the stem flow gauges, introduced by [6], is based on the principles of conservation of energy and mass, where all inputs and outputs are considered and works by applying a known amount of heat to a small segment of the stem from a thin flexible heater that surrounds the stem and is itself encircled by foam insulation. In general, this is known as the Stem Heat Balance (SHB) method [6] [7]. In steady state, heat input from the heater is balanced by the heat fluxes out of the stem. The heat output consists of four components: 1) conduction up the stem; 2) conduction down the stem; 3) radial conduction through the foam sheath; and 4) convection in the sap flow through the stem. Thus, the energy balance, inputs and outputs, of the heated stem is given by:

$$
P-\left(q_{a}+q_{r}+q_{c}+S\right)=0
$$

where $P$ is the power (heat flux) applied to the heater, $q_{a}$ is the axial heat loss, $q_{r}$ is the radial heat loss, $q_{c}$ is the convective heat loss, and $S$ is a storage term. The $q_{a}$ is the vertical axial conduction of heat along the upward $\left(q_{u}\right)$ and downward $\left(q_{d}\right)$ path of the heat flow, i.e., $q_{a}=q_{u}+q_{d}$. The magnitude of $S$ is small compared to the other terms in Equ- 
ation (1) and thus it assumed to be zero in small plants and has to be included when used in large trees [16]. This method requires a steady state and a constant energy input from the heater in the gauge surrounding the stem. All terms in Equation (1) have units of power, W. This method has been extensively tested on many agricultural crops and the general consensus is that the sap flux, as measured with stem flow gauges, is a direct measurement of the transpiration of the crop, i.e., $\mathrm{T}_{\text {crop. }}$. Examples on the use of this method are given by [6]-[8] [14]-[22] and many others.

The SHB method was used to design the stem flow gauges patented [23] [24] and sold by a commercial company (Dynamax Inc, Houston, TX, USA). The original stem flow gauge consists of a flexible heater that encircles the stem and provides a steady and known amount of heat. However, to improve sensor reliability with less maintenance and at a lower cost the original commercial stem flow gauge sensors were modified. These modifications included, e.g., different heater, insulation material and types of wire. In addition, the number and location of thermocouples used to measure the differential in temperature due to the flow of water were varied. All these modifications resulted in a new sensor, i.e., EXO-Skin ${ }^{T M}$ Sap Flow Sensor [25]. An obvious modification of the new sensor is the flexibility of the "skin" giving better thermal contact between the plant stem and the temperature sensors. Nevertheless, there are significant differences in the new sensor [25] compared to the original [23] [24], which warrant tests to evaluate their accuracy in measuring $\mathrm{T}_{\text {crop }}$. Therefore, our experimental objective was to measure hourly values of $\mathrm{T}_{\text {crop }}$ of cotton (Gossypium hirsutum, L.) by using the new stem flow gauge sensors (EXO-Skin ${ }^{T M}$ Sap Flow Sensor) [25] and to compare these values to gravimetric values measured on the same plants with lysimeters.

\section{Materials and Methods}

In the following sections we give a brief description on how the value of $\mathrm{T}_{\text {crop }}$ is calculated using the original and the new design of the stem flow gauges. These descriptions are given for clarity and to illustrate the differences between the two sensors. For additional information the reader is referred to the patents that describe each sensor in detail, i.e., the original sensor is given in [23] [24] and the new sensor is given in [25]. We also describe in detail the measurement of $\mathrm{T}_{\text {crop }}$ using the new stem flow gauge sensor and lysimeter on cotton plants. The statistical methods used to compare the values of $\mathrm{T}_{\text {crop }}$ measured with the new sensor and lysimeter are also given.

\subsection{Calculation of $\mathrm{T}_{\text {crop }}$ Using the Original Sap Flow Sensor}

The original SHB method works by applying a known amount of heat to a small segment of the stem from a thin flexible heater that surrounds the stem and is itself encircled by foam insulation and measuring a temperature difference above and below the heater (Figure 1). In steady state, heat input from the heater is balanced by the heat fluxes out of the stem, i.e., inputs = outputs as originally given by [6]. Following is a description on the SHB to calculate $\mathrm{T}_{\text {crop }}$ and for additional details the reader is referred to [6]-[24]. 


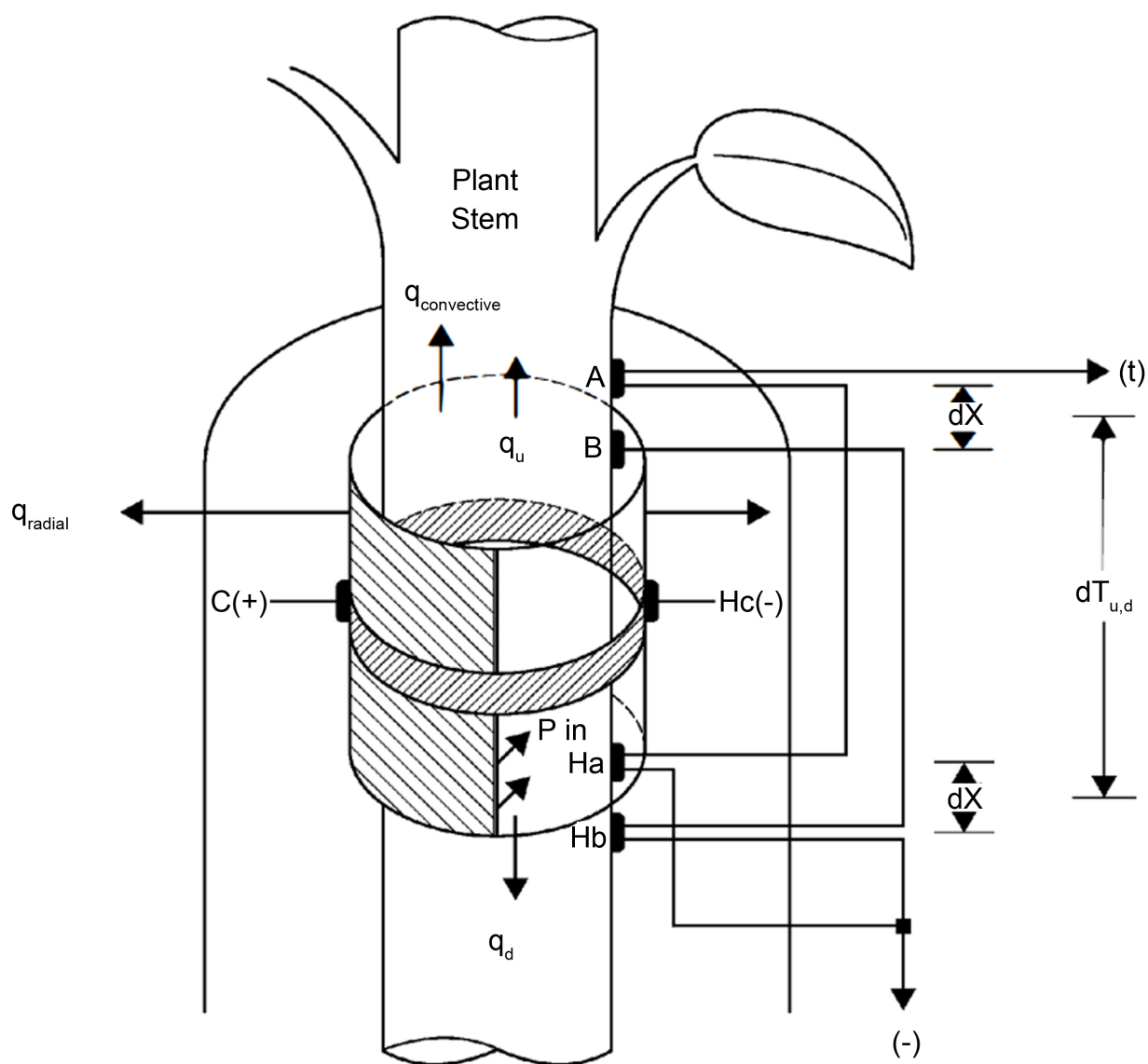

Figure 1. Schematic diagram of the original stem flow sensor showing the major components of the energy balance (adapted from [23]).

The power of the heater $(P)$ in Equation (1) is calculated from Ohm's Law given the input emf voltage $(E)(\mathrm{V})$ and the resistance $(R)$ of the heater (Ohms) as,

$$
P=\frac{E^{2}}{R} \text {. }
$$

Conductive fluxes above $\left(q_{u}\right)$ and below $\left(q_{d}\right)$ the heater in $\mathrm{W}$ are calculated by applying Fourier's Law:

$$
q_{u, d}=K_{s t} \times A \times \frac{d T_{u, d}}{d x}
$$

where $K_{s t}$ is the thermal conductivity of the stem $\left(\mathrm{W} / \mathrm{m} \cdot{ }^{\circ} \mathrm{C}\right), A$ is the cross sectional area of the stem $\left(\mathrm{m}^{2}\right)$, and $d T_{u, d} / d x$ are the measured temperature gradients $\left({ }^{\circ} \mathrm{C} / \mathrm{m}\right)$ above $\left(d T_{u}\right)$ and below $\left(d T_{d}\right)$ the heater. Temperature differences, $d T_{u, d}$ are measured with a pair of thermocouples separated by a distance $d x(\mathrm{~m})$. In Equation (3) a value of $0.422 \mathrm{~W} /\left(\mathrm{m} \cdot{ }^{\circ} \mathrm{C}\right)$ was used for $K_{s t}$ as suggested by several authors [7] [18]-[22].

The outward radial flow $\left(q_{r}\right)$ in $\mathrm{W}$ is calculated with,

$$
q_{r}=K_{\text {sh }} \times E
$$

where $K_{s h}$ is the sheath conductance $(\mathrm{W} / \mathrm{V})$ and $E$ is the output of the thermopiles lo- 
cated in the thin wrapper encircling the heater. The value of $K_{s h}$ is obtained when the sap flow rate $F$ is assumed to be $\approx 0$, i.e., at dawn, several hours before sunrise and is calculated by an algorithm provided by the manufacturer of the sensors.

The remaining term in Equation (1) is the convective heat flux carried by the mass transport of the sap $\left(q_{c}\right)$ in $\mathrm{W}$ and this value is calculated from the measured rise in temperature,

$$
q_{c}=C_{p} \times F \times\left(T_{u}-T_{d}\right)
$$

where $C_{p}$ is the volumetric heat capacity of water $\left(\mathrm{J} / \mathrm{kg} \cdot{ }^{\circ} \mathrm{C}\right), F$ is the sap flow rate in the stem $(\mathrm{kg} / \mathrm{s}), T_{u}$ and $T_{d}$ are the mean temperatures of sap flowing out of and into the system, respectively $\left({ }^{\circ} \mathrm{C}\right)$. The value of $F$ is equivalent to $\mathrm{T}_{\text {crop }}$.

Substituting Equations (3)-(5) into Equation (1), assuming that $S \approx 0$ and solving for the sap flux $F(\mathrm{~kg} / \mathrm{s})$ gives,

$$
F=\left[\frac{P-\left(K_{s t} \times A \times\left(\frac{d T_{u}+d T_{d}}{d x}\right)-K_{s h} \times E\right)}{C_{p} \times\left(T_{u}-T_{d}\right)}\right] .
$$

This equation is used in the original sap flow sensors [23] [24] to calculate $\mathrm{T}_{\text {crop }}$ with an algorithm provided by the manufacturer. The user has the option to specify, if so needed, values for $K_{s t}$ and $K_{s h}$. Examples on the measurement of $F$ on different plant species, e.g., grapes is given by [8], olives by [15], cotton by [17] [19], soybean by [20] [22], and in trees by [14] [16].

\subsection{Calculation of $\mathrm{T}_{\text {crop }}$ Using the New EXO-Skin ${ }^{\mathrm{TM}}$ Sap Flow Sensor}

The new EXO-Skin ${ }^{T M}$ Sap Flow Sensor [25] is also based on SHB; however, the placement and the number of thermocouples used to measure $d T_{u}$ and $d T_{d}$ was modified resulting in a new energy balance equation. In Figure 2, several thermocouples threaded with constantan copper wire used in the new sensor design are shown [25]. This is an example of EXO-Skin ${ }^{T M}$ Sap Flow model SGEX-13 (Dynamax Inc., Houston, TX) designed to accommodate plant stems with a $12-16 \mathrm{~mm}$ diameter.

In the new sensor design, the placement of the thermocouples, above and below the heater, is such that pairs of thermocouples are wired together, in parallel, resulting in one reading that causes a difference of +0.5 to $1.0^{\circ} \mathrm{C}$ in the measurement of $d T_{u, d}$ when compared to the original sensor [23] [24]. In this specific model, the upper thermocouple pair is $0.013 \mathrm{~m}$ above the heater and the lower pair is $0.018 \mathrm{~m}$ below the heater (Figure 2) and these distances vary according to the size (model) of the sensor used. In the new sensor design, the measurement of a single and averaged value of $d T_{u, d}$ eliminates one channel compared to the original design that uses two channels to record $d T_{u, d^{*}}$ A thermopile with multiple junctions is wired around the circumference of the heater and this is used to calculate $q_{r}$ as also done in the original sensor [23] [24].

The fundamental difference on the design of the new sap flow sensor is that $d T_{u, d}$ is measured by one reading; thus, eliminating the need to calculate $q_{u}$ and $q_{d}$ individually. 


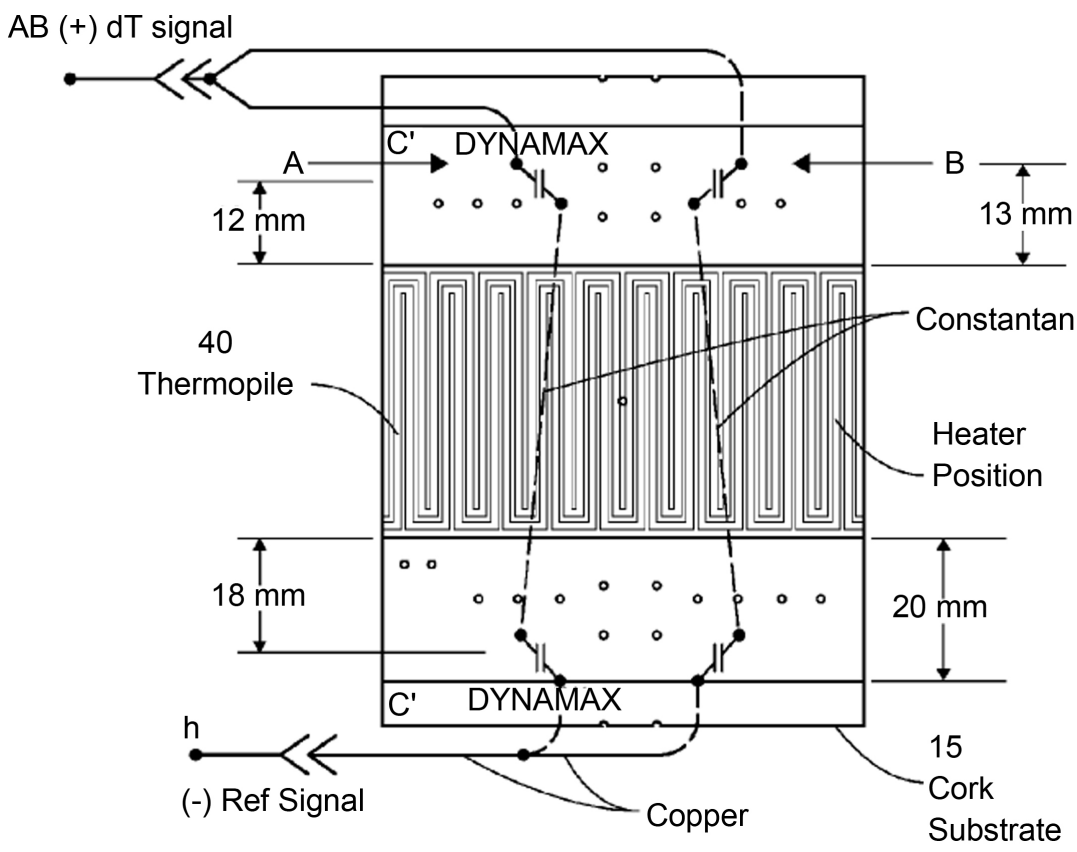

Figure 2. Example of the thermocouples threaded with constantan copper wire used in the new EXO-Skin ${ }^{T M}$ Sap Flow Sensor (model SGEX-13) [25].

Further, it is assumed that all energy losses by conduction are grouped into a single value of $q_{c}$ which is calculated from the radial thermopile that represents all heat conduction in and out of the stem. In preliminary tests it was shown that axial $\left(q_{a}\right)$ heat loss was $\sim 10 \%$ to $20 \%$ of the radial $\left(q_{r}\right)$ heat loss, and that when the two variables were combined into a single variable $\left(q_{f}\right)$, i.e., $q_{f}=q_{a}+q_{r}$, it resulted in a valid energy balance, i.e., inputs = outputs. Thus, the energy balance as given in Equation (1) reduces to:

$$
P=q_{c}+q_{f} .
$$

The sheath conductivity $\left(K_{s h}\right)$ is again calculated assuming $F \approx 0$ and thus calculated as,

$$
K_{s h}=\frac{P}{E} .
$$

In the new sensor, heat from conductivity is all derived from radial flow including any increase in $K_{s h}$ due to the grouping of $q_{a}$ and $q_{r}$ into a single variable. The end result of these modifications is that the value of $K_{s h}$ calculated with Equation (8) is $10 \%$ to $20 \%$ higher than the value calculated from Equation (4) that does include radial flow. By design in the new sensor the higher $K_{s h}$ means that the vertical (axial) heat conduction $q_{a}$ is included in $q_{\mathcal{o}}$ resulting in a representative conductance term in the energy balance. Therefore, $d T\left({ }^{\circ} \mathrm{C}\right)$ is calculated from the average temperature $\left(A_{h}\right.$ and $\left.B_{h}\right)$ measured with the two thermocouples (type T-thermocouple, $0.040 \mathrm{mV} /{ }^{\circ} \mathrm{C}$ ) as,

$$
d T=\left(\frac{A_{h}+B_{h}}{2}\right) \times 0.040 .
$$

Thus the value of $F$ is found from substituting into Equation (7) and rearranging 
terms as,

$$
F=\left[\frac{P-q_{c}}{C_{p}}\right] \times d T .
$$

The new sensors require less wiring and copper cable connectors, and because $d T$ is measured from an average temperature the number of data-logging channels is reduced by $25 \%$ when compared to the original design. In addition, the calculation of $F$ is simplified eliminating the area of the stem $(A)$, stem's thermal conductivity $\left(K_{s t}\right)$, see Equation (6), and specific sensor-constants that are required as input when using the original design [23] [24].

\subsection{Measurement of $\mathrm{T}_{\text {crop }}$ Using the New EXO-Skin ${ }^{\mathrm{TM}}$ Sap Flow Sensor}

Our experiments were done in a greenhouse located at the facilities of the Cropping Systems Research Laboratory, USDA-ARS, Lubbock TX $\left(33.59^{\circ} \mathrm{N}, 101.89^{\circ} \mathrm{W}\right.$, and average elevation of $960 \mathrm{~m}$ above sea level). Cotton (FiberMax ${ }^{\oplus}, 91880 \mathrm{~B} 2 \mathrm{~F}$, Bayer Crop Science, Research Triangle Park, NC) plants were grown in individual 11-liter (3 gallons) pots containing a commercial potting mixture. Cottonseeds were planted in early June 2014 and the test-period where $\mathrm{T}_{\text {crop }}$ measured with EXO-Skin ${ }^{T M}$ sensors [25] and using lysimeters were compared was for an 8-d period, from the 23 July to 30 July 2014, day of year (DOY) $204-211$.

Measurements of $\mathrm{T}_{\text {crop }}$ with the EXO-Skin ${ }^{T M}$ stem flow gauge sensors [25] started when the cotton stem diameter, as measured with a caliper, were $>9 \mathrm{~mm}$. For this purpose we used two models of the EXO-Skin ${ }^{T M}$ sensors, i.e., SGEX-10 and SGEX-13. The SGEX-10 model was used on stem diameters that ranged between 9.5 and $13 \mathrm{~mm}$, and the SGEX-13 model accommodated stem diameters between 12 and $16 \mathrm{~mm}$. We started with eight sensors numbered 1 - 8; however, sensor \#2, a 13-mm sensor, malfunctioned and was not used. The installation was done following the recommend procedure given by the manufacturer and care was followed to ensure that the wrapper of each EXO-Skin ${ }^{T M}$ sensor was in close thermal contact to the stem of the cotton plant. The outputs of the sensors were recorded with a datalogger (CR-3000, Campbell Scientific, Logan UT) with a built-in sap flow algorithm, i.e., Equation (10), provided by the manufacturer (Dynamax, Houston, TX). Measurements started on DOY 204 and ended on DOY 211. Output from each sensor was recorded on a 10-minute interval and transpiration values were calculated on an hourly basis for the 8-d measurement period.

To generate a range of transpiration values the potted cotton plants used in our experiments were individually watered at different rates between seedling-emergence and time that $\mathrm{T}_{\text {crop }}$ was measured with the stem flow gauge sensors and lysimeters. Each potted plant had a drip emitter placed on the surface of the container. Further, during the 8-d measurement period the amount of water applied to each cotton plant was varied. At the time when $\mathrm{T}_{\text {crop }}$ was measured with the stem flow gauge sensors the surface of each pot was covered with a plastic film to minimize evaporation of water from the potting mixture. 


\subsection{Measurement of $\mathrm{T}_{\text {crop }}$ Using Lysimeters}

On each plant with an EXO-Skin ${ }^{T M}$ stem flow gauge sensor [25], the changes in mass as a function time were measured gravimetrically by weighing the potted plant with load cells, i.e., using a lysimeter. The output from each lysimeter was recorded on a datalogger (CR-1000, Campbell Scientific, Logan UT) on a 5-minute time interval. We made sure that the time-stamp of the datalogger used with the EXO-Skin ${ }^{T M}$ stem flow gauge sensors and the datalogger used with the lysimeters were synchronized. We used sbeam tension and compression type load cells (LSB302, Futek Advanced Sensor Technology Inc., Irvine, CA) and each load cell had a maximum weighing capacity of $23 \mathrm{~kg}$. Each load cell was calibrated and provided a continuous record in $\mathrm{mV}$ that was converted to changes in mass in $\mathrm{kg}$. The calibration was done under laboratory conditions by placing certified calibration weights on the load cell plate and registering the corresponding output $(\mathrm{mV})$. This calibration indicated that a change in mass of $18.15 \mathrm{~g} / \mathrm{d}$ was equivalent to an evaporative water loss of $1.0 \mathrm{~mm} / \mathrm{d}$. Additional detail on the calibration and load cells used as lysimeters is given by [5].

\subsection{Comparison of $\mathrm{T}_{\text {crop }}$ Measured with Lysimetersand EXO-Skin ${ }^{\mathrm{TM}}$ Stem Flow Gauge Sensors}

To evaluate the EXO-Skin ${ }^{T M}$ sensors, we plotted the hourly and daily values of $\mathrm{T}_{\text {crop }}$ measured with the new sensors [25] as a function of the corresponding value measured with the lysimeters. This analysis was done for each of the seven sensors and for the pooled hourly and daily values of $\mathrm{T}_{\text {crop. }}$. In this comparison we did linear regression analysis and tested if the slope was significantly different than 1, i.e., slope $\neq 1$, and if the intercept was significantly different than 0 , i.e., intercept $\neq 0$. Both of these t-tests were done with a p-value of $>0.05$. A description of the procedures used is given by [26]. This statistical comparison was made for both hourly and daily values of $\mathrm{T}_{\text {crop }}$ for the test-period from DOY 204 to 211.

\subsection{Additional Measurements}

At the end of the test-period, on DOY 212, each cotton plant was harvested and the leaf area (LA) of each plant was measured using a leaf area meter (LI-3100C, Li-Cor, Lincoln, NE). The measurement of LA was used to convert $\mathrm{T}_{\text {crop }}$ measured with the EXO-Skin ${ }^{T M}$ sensors [25], see Equation (10), in $\mathrm{kg} / \mathrm{s}$ to volume of water per unit LA in $\mathrm{mm} / \mathrm{h}$. In this calculation we assumed a density of water of $1000 \mathrm{~kg} / \mathrm{m}^{3}$. In addition, ancillary measurements of the environmental conditions inside the greenhouse were made. These included air temperature and humidity (model HMP50-L, Campbell Scientific Inc., Logan, UT) and shortwave irradiance (model LI-200C, Li-Cor, Lincoln, NE) connected to a datalogger (CR-1000, Campbell Scientific, Logan UT) and all variables were measured at a $1 \mathrm{~Hz}$ frequency.

\section{Results and Discussion}

The results of the evaluation of the EXO-Skin ${ }^{T M}$ stem flow gauge sensors are presented 
for hourly and daily values of $\mathrm{T}_{\text {crop }}$. The comparison was made for $\mathrm{T}_{\text {crop }}$ values measured with the stem flow gauge sensors and lysimeters on the same cotton plant.

\subsection{Hourly Values of $\mathrm{T}_{\text {crop }}$}

As examples, hourly values of $\mathrm{T}_{\text {crop }}$ measured with EXO-Skin ${ }^{T M}$ stem flow gauge sensors and lysimeters, all as a function of DOY, across the 8-d measurement period are given in Figure 3. For this purpose we selected plants 3, 4, 7 and 8 for hourly values shown in Figure 3. To obtain a range of $\mathrm{T}_{\text {crop }}$ water was applied and withheld at different rates during the test period and as expected $\mathrm{T}_{\text {crop }}$ varied by the amount of water in each container. To illustrate the different patterns of hourly $\mathrm{T}_{\text {crop }}$ we selected four cotton plants shown in Figure 3.

In plant \#3, water was added at nighttime, from DOY 204 to 208, withheld on DOY 209 and again watered on DOY 210 (Figure 3(a)). These applications of water resulted in an increase of the hourly maximum values of $\mathrm{T}_{\text {crop }}$. For example, on DOY 204 and 205 the maximum $\mathrm{T}_{\text {crop }}$ was $\sim 80 \mathrm{~g} / \mathrm{h}$, on DOY 206 the maximum $\mathrm{T}_{\text {crop }}$ increased to 96 $\mathrm{g} / \mathrm{h}$, on DOY $207-209, \mathrm{~T}_{\text {crop }}$ maximum was $\sim 130 \mathrm{~g} / \mathrm{h}$, declining to $80 \mathrm{~g} / \mathrm{h}$ as a result of no water being applied on the previous night and increasing to $140 \mathrm{~g} / \mathrm{h}$ on DOY 211 when it was re-watered (Figure 3(a)). Cotton plant \#4 was watered daily, from DOY 204 to 211; however, this was the smallest plant in our experiments and the maximum
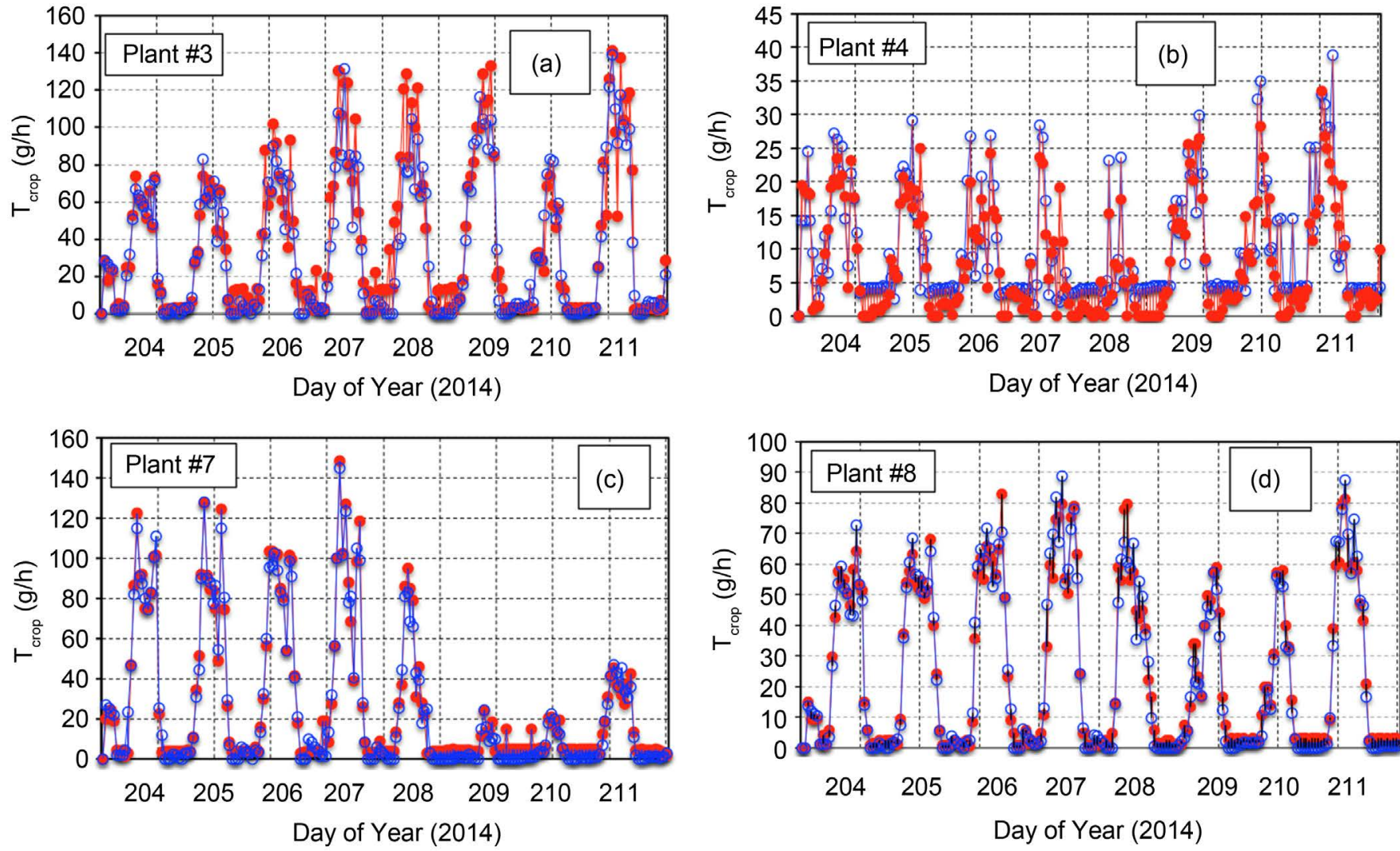

Figure 3. Hourly values of $\mathrm{T}_{\text {crop }}$ measured with the EXO-Skin ${ }^{T M}$ stem flow gauge sensors (open blue circles) and with lysimeters (solid red circles) on four cotton plants for the 8-d test period (DOY 204-211). 
hourly value of $\mathrm{T}_{\text {crop }}$ was $\sim 25 \mathrm{~g} / \mathrm{h}$ on the first five days and increased to $\sim 35 \mathrm{~g} / \mathrm{h}$ on the last two days (Figure 3(b)). Cotton plant \#7 (Figure 3(c)) and \#8 (Figure 3(d)) were watered daily from DOY 204 to 207 and water was withheld thereafter for the next three days and watered again on DOY 210. On both cotton plants, the EXO-Skin ${ }^{T M}$ stem flow gauge sensor captured this watering regime. On cotton plant \#7 the maximum $\mathrm{T}_{\text {crop }}$ on DOY $204-205$ was $\sim 120 \mathrm{~g} / \mathrm{h}$, declining to $100 \mathrm{~g} / \mathrm{h}$ on DOY 206, increasing to $150 \mathrm{~g} / \mathrm{h}$ on DOY 207, and thereafter declining as water was withheld (Figure $3(c))$. On DOY 208 the maximum $\mathrm{T}_{\text {crop }}$ was $95 \mathrm{~g} / \mathrm{h}$ and thereafter declined to $\sim 20 \mathrm{~g} / \mathrm{h}$ (DOY 209 - 210) and increased to $40 \mathrm{~g} / \mathrm{h}$ on DOY 211 (Figure 3(c)). A similar pattern was measured on cotton plant \#8 (Figure 3(d)) where the hourly value of maximum $\mathrm{T}_{\text {crop }}$ increased from $70 \mathrm{~g} / \mathrm{h}$ to $90 \mathrm{~g} / \mathrm{h}$ during DOY 204 to 208 , declined to $60 \mathrm{~g} / \mathrm{h}$ the next two days and then increased to $\sim 90 \mathrm{~g} / \mathrm{h}$ on DOY 211 (Figure 3(d)). The hourly values of $\mathrm{T}_{\text {crop }}$ measured with the EXO-Skin ${ }^{T M}$ stem flow gauge sensors and shown in Figure 3 are typical of values measured with the original sensor on potted plants in greenhouse experiments [27]-[29] and follow the hourly pattern of short-wave irradiance measured in the greenhouse.

\subsection{Daily Values of $\mathrm{T}_{\text {crop }}$}

The integrated hourly values of cotton $\mathrm{T}_{\text {crop }}$ shown in Figure 3 are plotted as daily values in Figure 4.
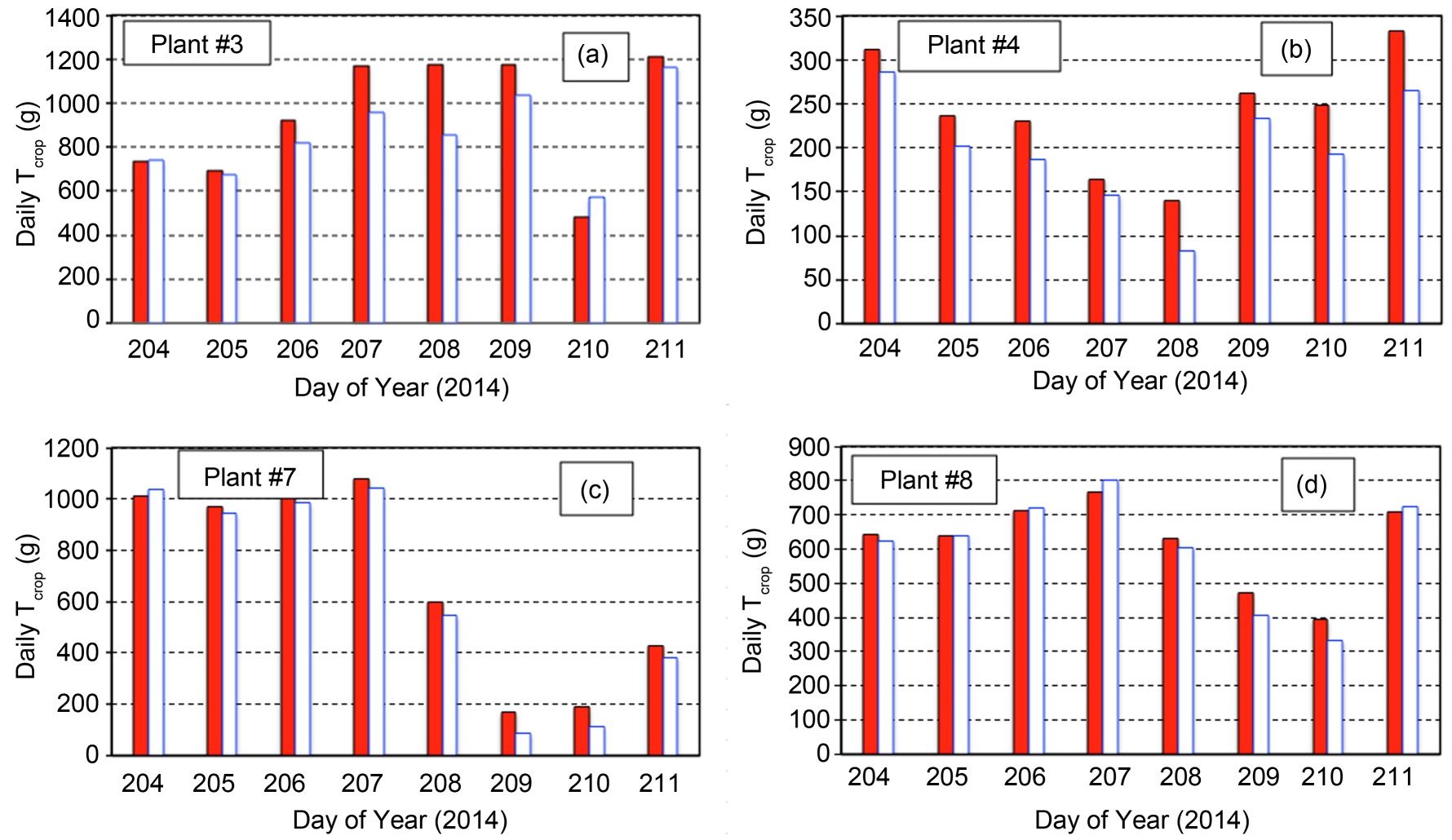

Figure 4. Daily values of $\mathrm{T}_{\text {crop }}$ measured with the EXO-Skin ${ }^{T M}$ stem flow gauge sensors (white column) and with lysimeters (red column) on four cotton plants for the 8-d test period (DOY 204-211). 
In general, the daily values of $\mathrm{T}_{\text {crop }}$ measured with the EXO-Skin ${ }^{T M}$ stem flow gauge sensors are in agreement with values measured with the lysimeters (Figure 4). However, there were discrepancies on several days and these varied by sensor. For example, on plant 3 (Figure $4(\mathrm{a})$ ), the sensors underestimated the daily value of $\mathrm{T}_{\text {crop }}$ by $210 \mathrm{~g}$ (18\%) on DOY 207, $321 \mathrm{~g}$ (27\%) on DOY 208, and overestimated $\mathrm{T}_{\text {crop }}$ by $91 \mathrm{~g}$ (19\%) on DOY 210. On plant \#4, the stem flow gauge sensors underestimated, on average by $40 \mathrm{~g}$ (17\%), the daily value of $\mathrm{T}_{\text {crop }}$ compared to the lysimeters (Figure 4(b)) with a similar result in plant \#7 (Figure 4(c)). However, on plant \#8 (Figure 4(d)) the daily values of $\mathrm{T}_{\text {crop }}$ measured with the stem flow gauges and lysimeters agreed within \pm 15 g, equivalent to $\pm 4 \%$, of each other.

\subsection{Statistical Comparison of $\mathrm{T}_{\text {crop }}$ Values}

A comparison of hourly values of $\mathrm{T}_{\text {crop }}$ measured with the EXO-Skin ${ }^{T M}$ stem flow gauge sensors as a function of hourly values of $\mathrm{T}_{\text {crop }}$ measured with the lysimeter are given in Figure 5. This comparison is a linear regression analysis for the four sensors shown in Figure 3 and Figure 4.

As expected and based on the comparison of hourly $\mathrm{T}_{\text {crop }}$ values shown in Figure 3 and for daily values shown in Figure 4, there is more scatter of values for measurements on plant \#3 (Figure 5(a)) and on plant \#4 (Figure 5(b)), compared to the other
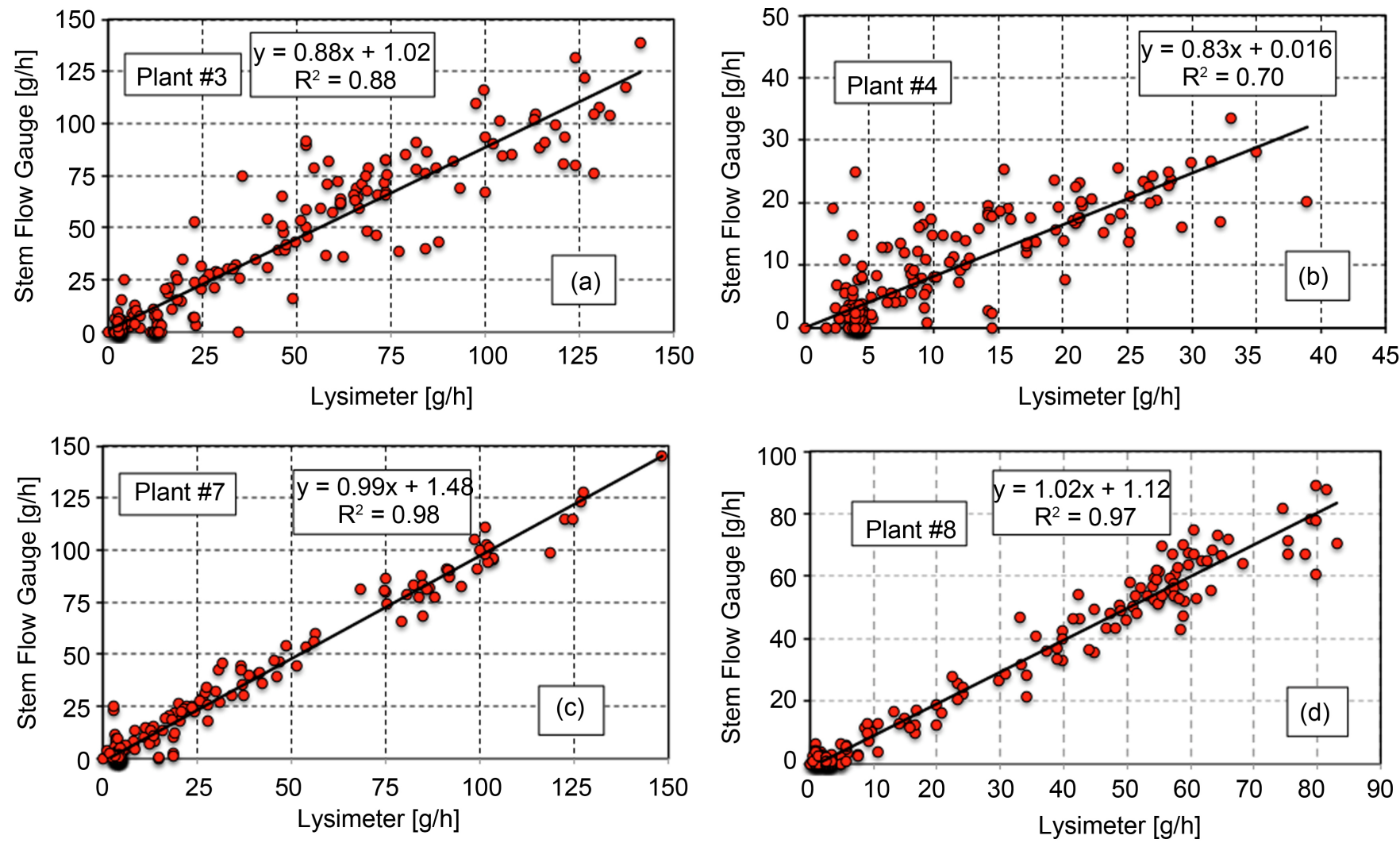

Figure 5. Linear regression analysis of hourly values of $\mathrm{T}_{\text {crop }}$ measured with the EXO-Skin ${ }^{T M}$ stem flow gauge sensors as a function of hourly values of $\mathrm{T}_{\text {crop }}$ measured with the lysimeters. For each plant the corresponding linear regression and coefficient $\left(\mathrm{R}^{2}\right)$ is given. 
two plants (Figure 5(c) and Figure 5(d)). Nevertheless, the slopes for both regressions are not statistically different than $1(\mathrm{p}>0.05)$ and the intercepts are not statistically different than $0(p>0.05)$. The regression analysis for the other two plants also yielded a slope not different than 1 and intercept not different than 0 for plant \#7 (Figure 5(c)) and plant \#8 (Figure 5(d)).

Pooling all the hourly $\mathrm{T}_{\text {crop }}$ measurements obtained across the 8-d period resulted in 1404 paired measurements of EXO-Skin ${ }^{T M}$ stem flow gauge and lysimeter measurements and the linear regression of these measurements is given in Figure 6. Similarly, pooling the integrated daily values of $\mathrm{T}_{\text {crop }}$ resulted in 56-paired measurements and the linear regression of these measurements is given in Figure 7.

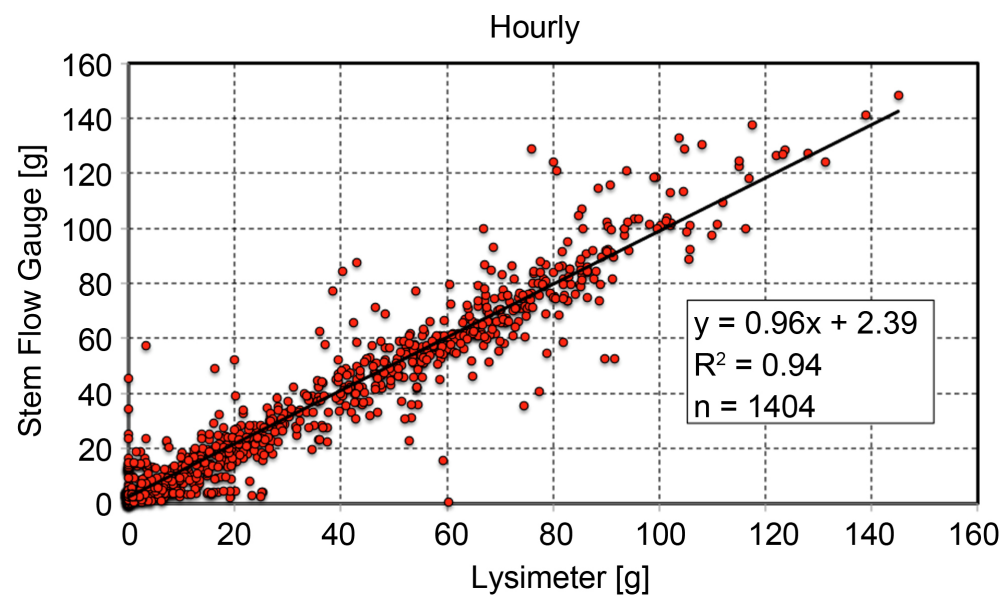

Figure 6. Hourly measured values of $\mathrm{T}_{\text {crop }}$ obtained the EXO-Skin ${ }^{T M}$ stem flow gauge sensors as a function of hourly measured values of $\mathrm{T}_{\text {crop }}$ obtained with lysimeters. Plotted is the pooled data obtained with seven sensors across the 8-d measurement period.

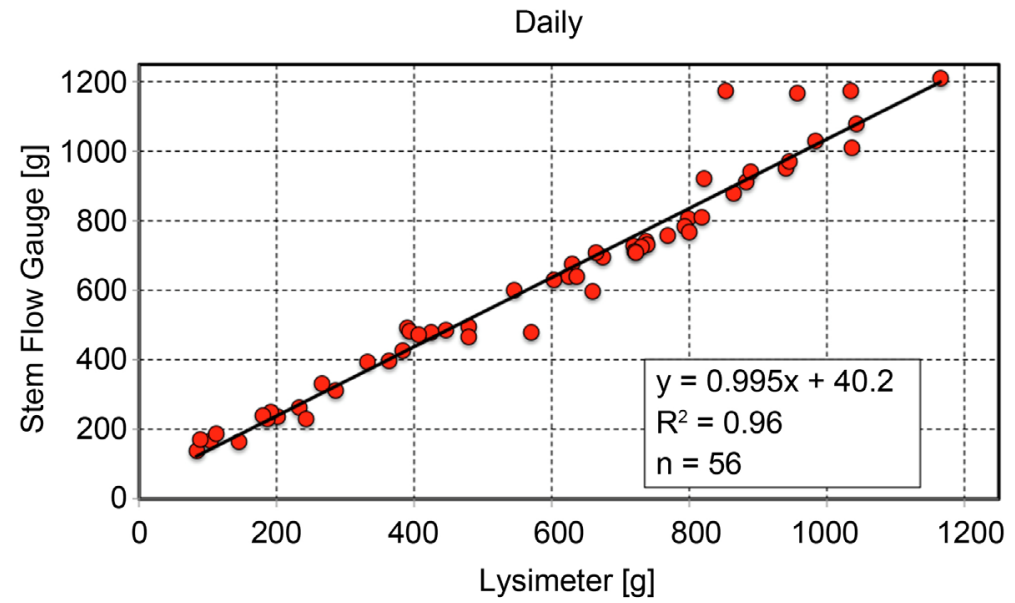

Figure 7. Daily measured values of $\mathrm{T}_{\text {crop }}$ obtained the EXO-Skin ${ }^{T M}$ stem flow gauge sensors as a function of daily values of $\mathrm{T}_{\text {crop }}$ obtained with lysimeters. Plotted is the pooled data obtained with seven sensors across the 8-d measurement period. 
Regression analysis on the pooled measurements of hourly and daily values of $T_{\text {crop }}$ indicated that the slopes of the lines were not different than $1(\mathrm{p}>0.05)$ and intercepts were not different than 0 ( $\mathrm{p}>0.05)$ as shown in Figure 6 and Figure 7, respectively.

The measured values of LA for each cotton plant on DOY 212 were $1.2 \mathrm{~m}^{2}$ for plant $\# 1,1.4 \mathrm{~m}^{2}$ for plant \#3, $1.6 \mathrm{~m}^{2}$ for plant \#4, $1.2 \mathrm{~m}^{2}$ for plant \#5, $1.4 \mathrm{~m}^{2}$ for plant \#6, 0.6 $\mathrm{m}^{2}$ for plant \#7, and $1.1 \mathrm{~m}^{2}$ for plant \#8. These values of LA are typical for potted plants grown in 11-liter containers. Values of LA were used to convert hourly values of $\mathrm{T}_{\text {crop }}$ obtained with Equation (10) in $\mathrm{kg} / \mathrm{s}$ to daily values in $\mathrm{mm} / \mathrm{d}$. As examples, the calculated daily values of $\mathrm{T}_{\text {crop }}$ in $\mathrm{mm} / \mathrm{d}$ for plant $\# 7$ and plant \#8 are shown in Figure 8. In these calculations the measured LA on DOY 212 was linearly extrapolated to DOY 204 assuming a $5 \%$ change in LA over the 8-d period (Figure 8).

These results (Figure 6 and Figure 7) showed that the modifications introduced in the design of the EXO-Skin ${ }^{T M}$ stem flow gauge sensors (Figure 2) did not affect the accuracy of the measurement of $\mathrm{T}_{\text {crop }}$. Therefore, we conclude that the new sensors correctly measured the $\mathrm{T}_{\text {crop }}$ of potted cotton plants in this greenhouse experiment. However, these results are for relatively small cotton plants and thus the low values of daily $\mathrm{T}_{\text {crop }}$ i.e., the maximum value of $\mathrm{T}_{\text {crop }}$ was $1.7 \mathrm{~mm} / \mathrm{d}$ on DOY 204 and 207 on plant \#7 (Figure 8). All other daily values of $\mathrm{T}_{\text {crop }}$ were $<0.9 \mathrm{~mm} / \mathrm{d}$ and the pattern across the 8-d measurement period was similar to plant \#8 (Figure 8).

The daily values of $T_{\text {crop }}$ in $\mathrm{mm} / \mathrm{d}$ shown in Figure 8 are low compared to field grown cotton plants and are typical of cotton in the seedling growth stage [5] [17]. In a semiarid climate daily values of $T_{\text {crop }}$ for irrigated cotton are on average $8 \mathrm{~mm} / \mathrm{d}$ and may exceed $11 \mathrm{~mm} / \mathrm{d}$ [17]. Nevertheless, these results have encouraged us to continue with field trials to further evaluate the EXO-Skin ${ }^{T M}$ stem flow gauges and this will be the subject of an upcoming paper.

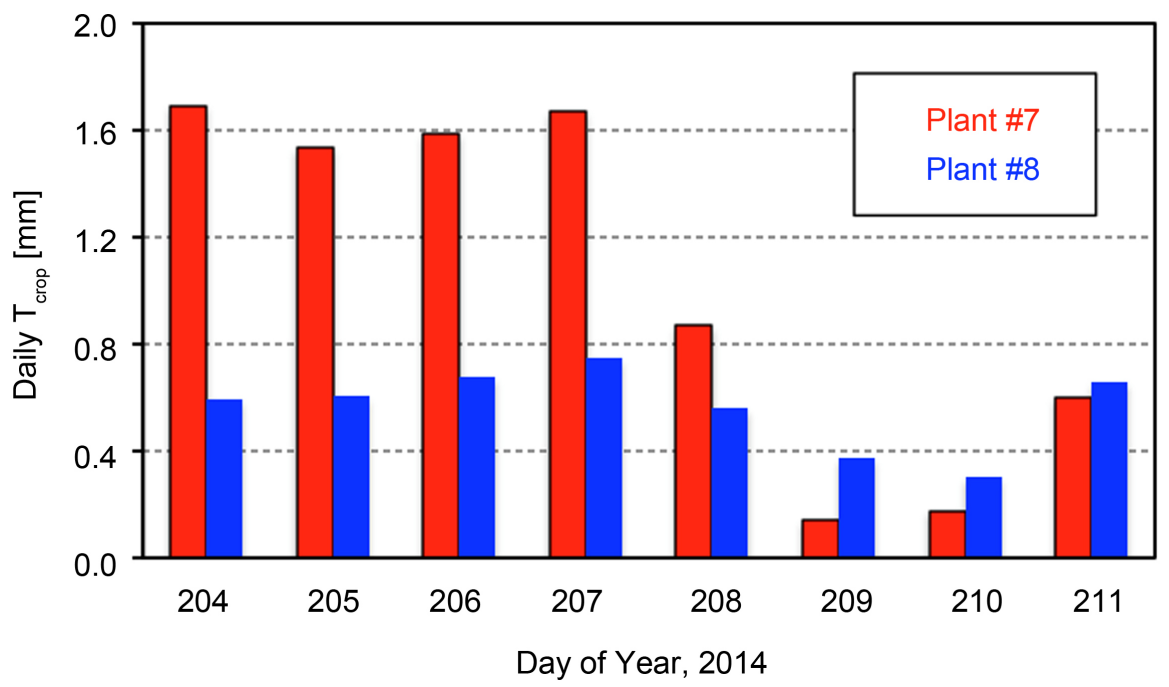

Figure 8. Daily values of $\mathrm{T}_{\text {crop }}$ obtained with the EXO-Skin ${ }^{T M}$ stem flow gauge sensors for cotton plant \#7 and \#8. The value of $\mathrm{T}_{\text {crop }}$ is the value measured by the stem flow gauge sensor and expressed per unit LA and thus $\mathrm{T}_{\text {crop }}$ has the unit of $\mathrm{mm} / \mathrm{d}$. 


\section{Summary and Conclusions}

Stem flow gauges to measure the transpiration of plants are based on the stem heat balance method, which uses the conservation of energy and mass and was introduced in 1981 [6]. This led to the development of commercially available sensors based on patented designs [23] [24]. The original design consists of measuring changes in temperature from thermocouples separated by a known distance obtained by wrapping a heater around the stem of a plant. This is known as a null method where inputs and outputs are known, and the sap heat flux $(F)$, i.e., $\mathrm{T}_{\text {crop }}$, is directly calculated using the measured change in temperature and physical constants that define the area $(A)$ and the thermal conductivity $\left(K_{s t}\right)$ of the stem (Equation (6)). One value, the sheath conductance $\left(K_{s h}\right)$, is calculated at nighttime when $F$ is close to 0 . This method has been extensively tested on several agronomic crops, vegetables, ornamentals and trees [6]-[8] [14]-[22]. The general consensus is that $F$ is a direct measure of $\mathrm{T}_{\text {crop. }}$.

The original sap flow sensor [23] [24] was modified (Figure 2) by changing the number and placement of thermocouples, resulting in a different energy balance to calculate $F$ (Equation (10)). These modifications are described in [25] and the new sensor is called EXO-Skin ${ }^{T M}$ stem flow gauges. The difference between the original and the new sap flow sensor is that the new sensor uses less wiring and copper connectors, and the number of channels used to record the signal in a data-logger is reduced by $1 / 4$. Further, input on the area and thermal conductivity of the stem and sensor-specific constants are eliminated (Equation (10)). An obvious improvement of the new sensor is the flexibility of the heater that allows better thermal contact between the plant stem and the temperature sensors.

The modifications between the original and new stem flow gauge sensors are significant, warranting tests to corroborate that the measurements of $\mathrm{T}_{\text {crop }}$ with the new sensor are correct. Therefore, our experimental objective was to measure and to compare the measurement of $\mathrm{T}_{\text {crop }}$ with the new sensors and with lysimeters. For this purpose, cotton plants were grown in 11-liter pots in a greenhouse and hourly values of $\mathrm{T}_{\text {crop }}$ measured with EXO-Skin ${ }^{T M}$ stem flow gauges and with lysimeters on the same plant were compared across an 8-d period. Our results showed that the new sensors correctly measured the $\mathrm{T}_{\text {crop }}$ of cotton plants. This conclusion is based on linear regression analysis, EXO-Skin ${ }^{T M}$ stem flow gauge vs. lysimeters values of $\mathrm{T}_{\text {crop }}$, indicating that the slope of the line was not statistically different than 1 and the intercept was not statistically different than $0(\mathrm{p}>0.05)$. These measurements were done under conditions that resulted in $\mathrm{T}_{\text {crop }}$ values $<2 \mathrm{~mm} / \mathrm{d}$ due to limited size of the containers used in our experiments. We conclude that the measurements of $\mathrm{T}_{\text {crop }}$ obtained with the EXO-Skin ${ }^{T M}$ stem flow gauges sensors [25] are a direct measurement of the transpiration of the cotton plants used in our experiments. Given that the values of daily $\mathrm{T}_{\text {crop }}$ are $<2 \mathrm{~mm} / \mathrm{d}$, additional tests with plants under field conditions are needed.

\section{Acknowledgements}

This research was supported in part by the Ogallala Aquifer Program, a consortium 
between USDA-Agricultural Research Service, Kansas State University, Texas A\&M AgriLife Research, Texas A\&M AgriLife Extension Service, Texas Tech University, and West Texas A\&M University. A Material Transfer Research Agreement between the USDA-ARS and Dynamax, Inc., also provided funds and equipment used in this project. Figure 1 and Figure 2 are used with the permission of M. G. van Bavel, President, Dynamax, Inc.

\section{Declaration}

Mention of trade names or commercial products in this publication is solely for the purpose of providing specific information and does not imply recommendation or endorsement by the U.S. Department of Agriculture. The USDA is an equal opportunity provider and employer.

\section{References}

[1] Lascano, R.J. (2007) The Soil-Plant-Atmosphere System and Monitoring Technology. In: Lascano, R.J. and Sojka, R.E., Eds., Irrigation of Agricultural Crops, American Society of Agronomy, Crop Science Society of America, and Soil Science Society of America, Madison, 85-115. http://dx.doi.org/10.2134/agronmonogr30.2ed.c3

[2] Schneider, A.D., Howell, T.A. and Steiner, J.L. (1992) An Evaporation Research Facility Using Monolithic Lysimeters from Three Soils. Applied Engineering in Agriculture, 9, 227-232. http://dx.doi.org/10.13031/2013.25982

[3] Schneider, A.D., Howell, T.A., Moustafa, A.T.A., Evett, S.R. and Abou-Zeid, W. (1998) A Simplified Weighing Lysimeter for Monolithic or Reconstructed Soils. Applied Engineering in Agriculture, 14, 267-273. http://dx.doi.org/10.13031/2013.19388

[4] Marek, T., Piccinni, G., Schneider, A., Howell, T., Jett, M. and Dusek, D. (2006) Weighing Lysimeters for the Determination of Crop Water Requirements and Crop Coefficients. $A p$ plied Engineering in Agriculture, 22, 851-856. http://dx.doi.org/10.13031/2013.22256

[5] Lascano, R.J., Duesterhaus, J.L., Booker, J.D., Goebel, T.S. and Baker, J.T. (2014) Field Measurement of Cotton Seedling Evapotranspiration. Agricultural Sciences, 5, 1237-1252. http://dx.doi.org/10.4236/as.2014.513132

[6] Sakuratani, T. (1981) A Heat Balance Method for Measuring Water Flux in the Stem of Intact Plants. Journal of Agricultural Meteorology, 37, 9-17. http://dx.doi.org/10.2480/agrmet.37.9

[7] Baker, J.M. and van Bavel, C.H.M. (1987) Measurement of Mass Flow of Water in the Stems of Herbaceous Plants. Plant, Cell and Environment, 10, 777-782.

[8] Lascano, R.J., Baumhardt, R.L. and Lipe, W.N. (1992) Measurement of Water Flow in Young Grapevines Using the Stem Heat Balance Method. American Journal of Enology and Viticulture, 43, 159-165.

[9] Baker, J.T., Gitz III, D.C. and Lascano, R.J. (2014) Field Evaluation of Open System Chambers for Measuring Whole Canopy Gas Exchanges. Agronomy Journal, 106, 537-544. http://dx.doi.org/10.2134/agronj2013.0449

[10] Baker, J.T., Gitz III, D.C., Payton P., Broughton, K.J., Bange, M.P. and Lascano, R.J. (2014) Carbon Dioxide Control in an Open System that Measures Canopy Gas Exchanges. Agronomy Journal, 106, 789-792. http://dx.doi.org/10.2134/agronj13.0450

[11] Baker, J.T., Van Pelt, S., Gitz, D.C., Payton, P., Lascano, R.J. and McMichael, B. (2009) Ca- 
nopy Gas Exchange Measurements of Cotton in an Open System. Agronomy Journal, 101, 52-59. http://dx.doi.org/10.2134/agronj2008.0007x

[12] Todd, R.W., Evett, S.R. and Howell, T.A. (2000) The Bowen Ratio-Energy Balance Method for Estimating Latent Heat Flux of Irrigated alfalfa Evaluated in a Semi-Arid, Advective Environment. Agricultural and Forest Meteorology, 103, 335-348.

http://dx.doi.org/10.1016/S0168-1923(00)00139-8

[13] Irmak, S., Skaggs, K.E. and Chatterjee, S. (2014) A Review of the Bowen Ratio Surface Energy Balance Method for Quantifying Evapotranspiration and Other Energy Fluxes. Transactions of the ASABE, 57, 1657-1674.

[14] Wilson, K.B., Hanson, P.J., Mulholland, P.J., Baldocchi, D.D. and Wullschleger, S.D. (2001) A Comparison of Methods for Determining Forest Evapotranspiration and Its Components: Sap-Flow, Soil Water Budget, Eddy Covariance and Catchment Water Balance. Agricultural and Forest Meteorology, 106, 153-168. http://dx.doi.org/10.1016/S0168-1923(00)00199-4

[15] Cammalleri, C., Rallo, G., Agnese, C., Ciraolo, G., Minacapilli, M. and Provenzano, G. (2013) Combined Use of Eddy Covariance and Sap Flow Techniques for Partition of ET Fluxes and Water Stress Assessment in an Irrigated Olive Orchard. Agricultural Water Management, 120, 89-97. http://dx.doi.org/10.1016/j.agwat.2012.10.003

[16] Grime, V.L., Morison, J.I.L. and Simmonds, L.P. (1995) Including the Heat Storage Term in Sap Flow Measurements with the Stem Heat Balance Method. Agricultural and Forest Meteorology, 74, 1-25. http://dx.doi.org/10.1016/0168-1923(94)02187-O

[17] Lascano, R.J. (2000) A General System to Measure and Calculate Daily Crop Water Use. Agronomy Journal, 92, 821-832. http://dx.doi.org/10.2134/agronj2000.925821x

[18] Steinberg, S., Van Bavel, C.H.M. and McFarland, M.J. (1989) A Gauge to Measure Mass Flow Rate of Sap in Stem and Trunks of Woody Plants. Journal of the American Society for Horticultural Science, 114, 466-472.

[19] Ham, J.L., Heilman, J.L. and Lascano, R.J. (1990) Determination of Soil Water Evaporation and Transpiration from Energy Balance and Stem Flow Measurements. Agricultural and Forest Meteorology, 52, 287-301. http://dx.doi.org/10.1016/0168-1923(90)90087-M

[20] Tan, C.S. and Buttery, B.R. (1995) Determination of the Water Use of Two Pair of Soybean Isolines Differing in Stomatal Frequency Using a Stem Heat Balance Stem Flow Gauge. Canadian Journal of Plant Sciences, 75, 99-103. http://dx.doi.org/10.4141/cjps95-016

[21] Smith, D.M. and Allen, S.J. (1996) Measurement of Sap Flow in Plant Stems. Journal of Experimental Botany, 47, 1833-1844. http://dx.doi.org/10.1093/jxb/47.12.1833

[22] Sauer, T.J., Singer, J.W., Prueger Thomas, J.H., DeSutter, M. and Hatfield, J.L. (2007) Radiation Balance and Evaporation Partitioning in a Narrow-Row Soybean Canopy. Agricultural and Forest Meteorology, 145, 206-214. http://dx.doi.org/10.1016/j.agrformet.2007.04.015

[23] Van Bavel, C.H.M. and Van Bavel, M.G. (1993) Apparatus for Measuring Sap Flow. US Patent No. 5269183.

[24] Van Bavel, C.H.M. and Van Bavel, M.G. (1994) Apparatus for Measuring Sap Flow. US Patent No. 5337604.

[25] Van Bavel, M.G. (2013) Sap Flow Sensor Apparatus. US Patent 8590373 B1.

[26] Kobayashi, K. and Salam, M.U. (2000) Comparing Simulated and Measured Values Using Mean Squared Deviation and Its Components. Agronomy Journal, 92, 345-352. http://dx.doi.org/10.2134/agronj2000.922345x

[27] Escalona, J., Flexas, J. and Medrano, H. (2002) Drought Effects on Water Flow, Photosynthesis and Growth of Potted Grapevines. Vitis, 41, 57-62. 
[28] Rose, M.A. and Rose, M.A. (1994) Oscillatory Transpiration May Complicate Stomatal Conductance and Gas-Exchange Measurements. HortScience, 29, 693-694.

[29] Gavloski, J.E., Whitfield, G.H. and Ellis, C.R. (1992) Effect of Restricted Watering on Sap Flow and Growth in Corn (Zea mays L.). Canadian Journal of Plant Science, 72, 361-368. http://dx.doi.org/10.4141/cjps92-040

Submit or recommend next manuscript to SCIRP and we will provide best service for you:

Accepting pre-submission inquiries through Email, Facebook, LinkedIn, Twitter, etc. A wide selection of journals (inclusive of 9 subjects, more than 200 journals)

Providing 24-hour high-quality service

User-friendly online submission system

Fair and swift peer-review system

Efficient typesetting and proofreading procedure

Display of the result of downloads and visits, as well as the number of cited articles

Maximum dissemination of your research work

Submit your manuscript at: http://papersubmission.scirp.org/

Or contact as@scirp.org 